\title{
Retinal Degeneration and Regeneration-Lessons From Fishes and Amphibians
}

\author{
Divya Ail ${ }^{1} \cdot$ Muriel Perron ${ }^{1,2}$ \\ Published online: 25 January 2017 \\ (C) The Author(s) 2017. This article is published with open access at Springerlink.com
}

\begin{abstract}
Purpose of Review Retinal degenerative diseases have immense socio-economic impact. Studying animal models that recapitulate human eye pathologies aids in understanding the pathogenesis of diseases and allows for the discovery of novel therapeutic strategies. Some nonmammalian species are known to have remarkable regenerative abilities and may provide the basis to develop strategies to stimulate self-repair in patients suffering from these retinal diseases.

Recent Findings Non-mammalian organisms, such as zebrafish and Xenopus, have become attractive model systems to study retinal diseases. Additionally, many fish and amphibian models of retinal cell ablation and cell lineage analysis have been developed to study regeneration. These investigations highlighted several cellular sources for retinal repair in different fish and amphibian species. Moreover, major differences in repair mechanisms have been reported in these animal models.

Summary This review aims to emphasize first on the importance of zebrafish and Xenopus models in studying the pathogenesis of retinal diseases and, second, on the different modes of regeneration processes in these model organisms.
\end{abstract}

This article is part of the Topical Collection on Xenopus and Zebrafish Models for Pathobiology

Muriel Perron

muriel.perron@u-psud.fr

1 Paris-Saclay Institute of Neuroscience, CNRS, Univ. Paris-Sud, Université Paris-Saclay, Orsay, France

2 Centre d'Etude et de Recherche Thérapeutique en Ophtalmologie, Retina France, Orsay, France
Keywords Retinal degeneration $\cdot$ Retinal regeneration Retinal stem cells $\cdot$ Müller glial cells · Ciliary marginal zone · Retinal pigment epithelium

\section{Introduction}

Retinal diseases resulting in impaired vision and blindness both severely compromise the quality of life of the individual and have proven to be socio-economic burdens. Hence, a substantial amount of research efforts in the field are directed towards understanding the disease mechanisms and developing therapies to combat these disorders.

The clinical trial success of an AAV-mediated gene therapy to correct the RPE65 mutation causing Leber congenital amarousis (LCA) [1,2] is encouraging the use of this strategy for other diseases with distinct genetic causes. However, such therapies do not hold much potential in the case of Retinitis pigmentosa (RP), wherein more than 200 different mutations affecting 50 different genes have been linked to the disease [3]. Another complex, multi-factorial disease is age-related macular degeneration (AMD), which has factors such as age and lifestyle $[4,5]$ in addition to genes [6] that contribute to the onset of symptoms, progression of the disease, and response to the limited therapies. AMD is classified into wet or dry depending on the occurrence or lack of neovascularization, respectively. The randomly formed blood vessels leak blood and fluids into the retina resulting in rapid and severe retinal damage. The most widely accepted anti-vascular endothelial growth factor (VEGF) therapy is provided only for wet AMD patients who account for $15 \%$ of the total AMD cases $[7,8]$. Several therapies are provided to delay the onset or slow down the progression of the disease, with varying degrees of success [9]. However, a therapy for those suffering from dry AMD still remains an unmet medical need. Cell 
replacement therapies attempt to replace lost neuronal cells of the retina with retinal progenitors or pre-differentiated cells $[10,11]$. Attempts to restore rod function and vision in murine models of retinal degeneration proved successful [12]. This further encouraged cell replacement studies, using cells derived from 3D cultures of embryonic cells [13] as well as the more recent transplantation of human embryonic stem cell (hESC)-derived retinal tissue into primate models of retinal degeneration [14•]. Retinal pigment epithelium (RPE) cells have been successfully replaced by cells originating from ESCs [15], bone marrow-derived hematopoietic stem cells (BMHSCs) [16], or induced pluripotent stem cells (iPSCs) $[17,18]$. Although some of these therapies have slowly made the transition from the research laboratories to clinical trials [19-20,21•], the ability of the transplanted cells to integrate in the local environment, make the right connections, and restore vision will eventually determine their efficacy as actual treatments. Unexpectedly, two recent studies showed that stem cell-derived photoreceptor progenitors transplanted into the murine retina do not actually integrate within the retina as previously suggested. These transplanted cells stay in the subretinal space at the site of injection and are involved in an exchange of cytoplasmic material with the host photoreceptors $[22 \cdot, 23 \bullet]$. On the other end of the spectrum, technological advances in the field of retinal prosthesis have led to the development of retinal implants that allow partial restoration of low-resolution vision in some patients, which enables them to perceive light and discern large objects. These implants work by electrically stimulating the surviving neurons in the diseased retina [24].

All these multi-faceted attempts to fight visual impairment and loss are owing to the fact that the mammalian retina is incapable of repairing or regenerating itself. Once the mammalian retinal neurons are lost due to injury or disease, they cannot be restored by endogenous mechanisms. However, there are many species including zebrafish and Xenopus that are known to have remarkable regenerative abilities. Understanding these mechanisms and manipulating them could allow for the development of an alternative therapeutic strategy aimed at triggering self-repair in the mammalian retina.

The mammalian retina is composed of stratified layers of five different types of neurons. Photoreceptors (rods and cones) are present in the outer nuclear layer (ONL) and form connections with horizontal cells, bipolar cells, and amacrine cells present in the inner nuclear layer (INL), which further connect to the ganglion cells in the ganglion cell layer (GCL). There are three types of glial cells in the retina, Müller cells, astrocytes, and microglia. The Müller cells originate from the same retinal progenitor as all retinal neurons [25], and they span all the layers of the retina making connections with and providing support to all the cell types. A single-cell layer of epithelial cells called RPE is present between the choroid and the outer segments of the photoreceptors (Fig. 1a, b). Major blinding diseases of the retina, such as AMD or RP, result from the direct loss of photoreceptors or follow the loss of RPE cells.

In addition to these cell types, the retinas of zebrafish and Xenopus have a region at the peripheral part of the retina composed of stem cells and progenitor cells that generate retinal cells in the larvae and adult eye. This region is called the ciliary margin zone (CMZ) and is composed of cells that are present in a spatial gradient: the extreme edge of the CMZ is occupied by stem cells, followed by committed proliferating retinal progenitors and finally post-mitotic progenitors [26-28] (Fig. 1a, c).

\section{Zebrafish and Xenopus Models for Degeneration and Regeneration Studies}

\section{Models to Study Retinal Degenerative Diseases}

Often retinal dystrophies have a genetic cause, and the onset and progression of the disease is gradual. Hence, attempts are being made to reproduce disease mutations in animal models to understand the pathogenic mechanisms of degeneration. Comprehensive reviews on the use of zebrafish models to study a broad range of retinal diseases have recently been published [29•, 30-31]. Here, we provide a few recent examples, highlighting the relevance of these models to study human retinal dystrophies. There are several models for retinal diseases affecting photoreceptor survival in zebrafish, wherein genes crucial for phototransduction have been mutated. For instance, mutation in the cone phosphodiesterase $\alpha$-subunit gene ( $p d e 6 c$ ) causes cone degeneration followed by rod cell death, as observed in humans [32]. This zebrafish model allowed to better understand the underlying mechanism of cone and rod cell death and thus to propose that a combination therapy intervention in patients, directed at the different cell death mechanisms, could provide effective treatment strategies [33]. Many zebrafish mutants with photoreceptor degeneration carry mutations in cilia-related genes, which are important for proper intracellular trafficking. These models recapitulate various retinal ciliopathies in humans, such as the Bardet-Biedl syndrome (BBS) or the Joubert syndrome. Three recent reports exemplify the usefulness of zebrafish models to provide phenotype-genotype correlations or to discover novel genetic interactions related to retinal ciliopathies: a knockdown approach in zebrafish revealed a ciliary function for $v p s 15$, a gene in which mutations are found in patients with a ciliopathy [34•]; by overexpressing in zebrafish mutated forms of the $C 8 O R F 37$ gene, encoding a cilia protein, it was shown that $C 8 O R F 37$ variants cause BBS [35•]; the zebrafish mutant for $a r l 13 b$, a gene that causes the classical form of Joubert syndrome, revealed that Arl13b genetically and 

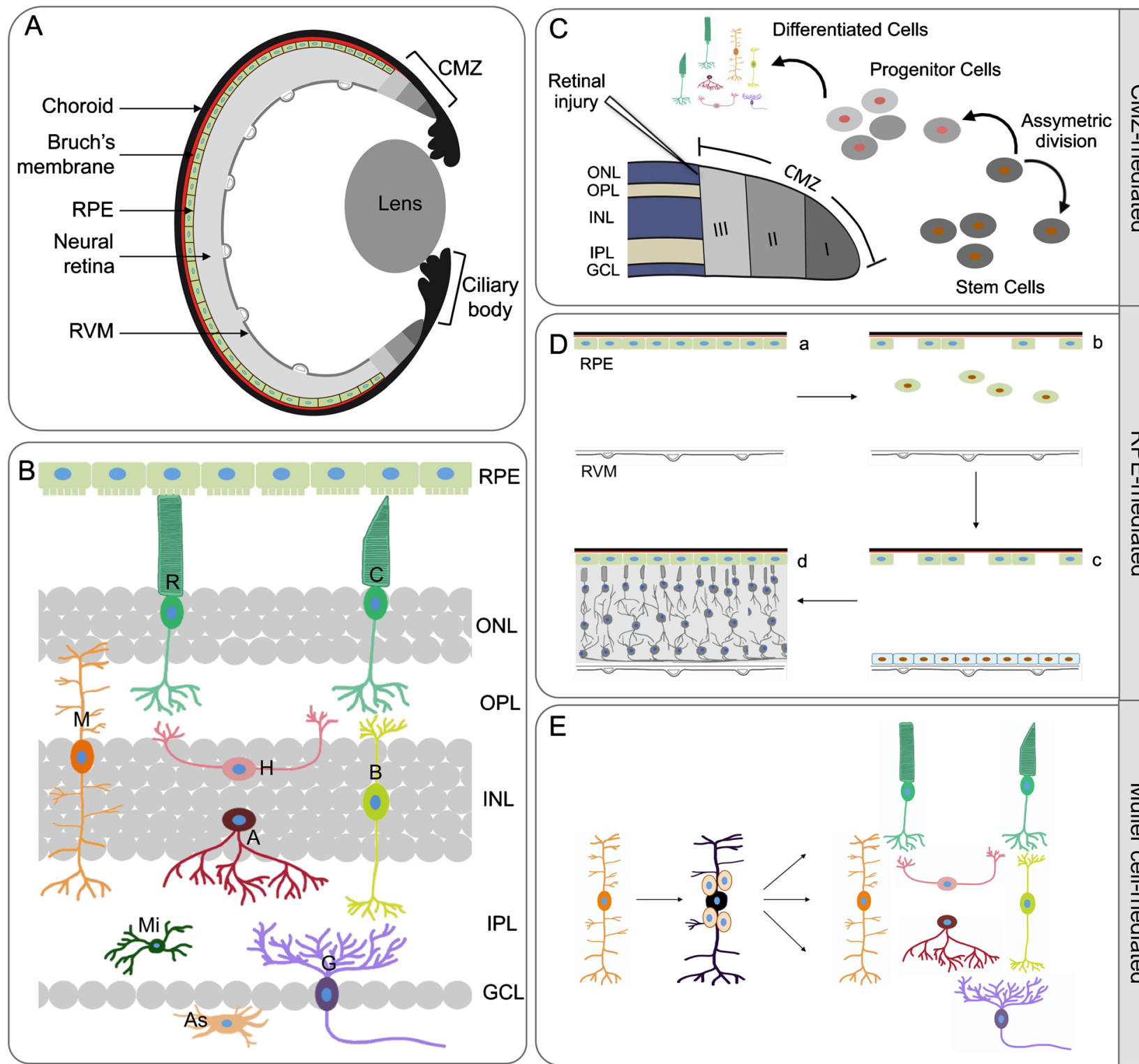

\section{E}
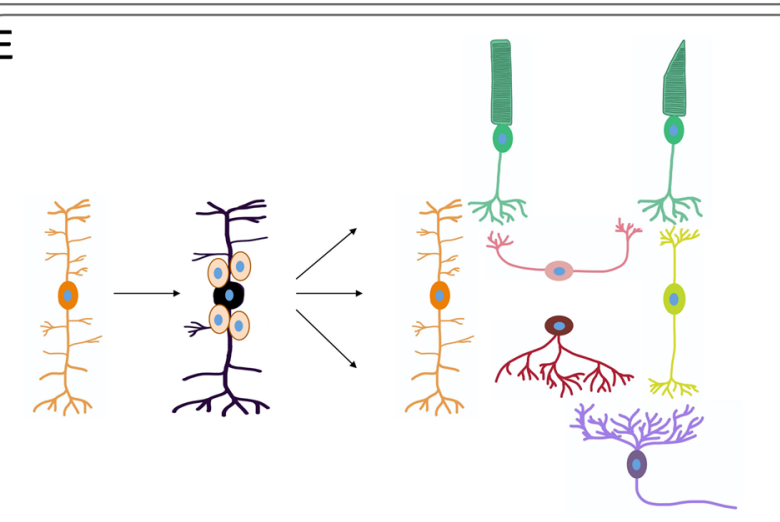

Fig. 1 a Structure of the retina. Schematic representation of a cross section of the zebrafish or Xenopus eye showing the ciliary marginal zone (CMZ), retinal pigment epithelium (RPE), neural retina, choroid, Bruch's membrane, and the retinal vascular membrane (RVM). b Cell types of the retina. The retina is composed of different cell types: the nuclei of the two types of photoreceptors, rods (R) and cones (C), form the outer nuclear layer (ONL), whereas the Müller cells (M), horizontal cells $(\mathrm{H})$, bipolar cells (B), and amacrine cells (A) are present in the inner nuclear layer (INL), and the ganglion cells $(\mathrm{G})$ in the ganglion cell layer (GCL). The axons of these neurons and glial cells form synaptic connections in the outer and inner plexiform layers (OPL and IPL). The astrocytes (As) are located near the blood vessels whereas the microglia (Mi) are mostly located in the plexiform layers but can be distributed through the different layers. c-e Modes of regeneration and repair. CMZ-mediated (c): In the constantly growing retinas of zebrafish and Xenopus, the spatial cellular gradient in the CMZ recapitulates embryonic retinogenesis with zone I, the most peripheral part of the

physically interacts with the planar cell polarity protein (PCP) component Vang12 and that this association is important for normal photoreceptor structure [36]. The feasibility of large-
$\mathrm{CMZ}$, where stem cells reside, zone II encompassing retinal progenitor cells, and zone III consisting of late retinal progenitors including postmitotic retinoblasts. The stem cells divide asymmetrically to self-renew and generate one progenitor cell, and this mode of asymmetric division is retained even in the case of retinal injury. RPE-mediated (d): In Xenopus following partial retinectomy, wherein the RPE and RVM are left intact (a), a subset of RPE cells (green oval cells) detach from the Bruch's membrane (in red) and migrate to the RVM (b). When they adhere to the RVM and form a distinct layer of cells (blue cells), they start proliferating $(c)$ and regenerate the whole neural retina $(d)$, while RPE cells that remained attached to the Bruch's membrane renew the RPE layer $(d)$. Müller-cell mediated (e): In zebrafish upon retinal injury, a subset of Müller cells (orange) undergo asymmetric division (black) to renew themselves and generate multipotent progenitor cells that can actively divide and regenerate all major retinal cell types (color figure online)

scale screens is clearly an advantage of using zebrafish as an animal model for human diseases. As an example, a wholegenome siRNA-based functional genomics screen was used to 
identify genes whose activity is required for ciliogenesis and/ or cilia maintenance. This approach allowed the identification of a collection of ciliopathy genes and brought insights into pathogenic mechanisms of ciliopathies [37•]

Angiogenesis significantly contributes to the progression of retinal diseases such as AMD and diabetic retinopathy. Some zebrafish models have been generated to study retinal pathological angiogenesis. For instance, neovascularization is observed in zebrafish subjected to hypoxia or in von HippelLindau (VHL) tumor suppressor mutants [38-40]. Immersing zebrafish in glucose solution induces hyperglycemia and serves as a model for diabetic retinopathy [41, 42]. Interestingly, it was shown that vascular changes are not sufficient to induce cone photoreceptor dysfunction, suggesting that the vascular and neuronal complications in diabetic retinopathy can arise independently. All these models for pathological angiogenesis and vascular retinopathies offer costeffective ways to screen in vivo for efficient novel antiangiogenic drugs [43].

Although Xenopus is not as genetically amenable as zebrafish, it has nonetheless emerged as a relevant model to study retinal diseases $[44,45]$. Fourier domain optical coherence tomography (FD-OCT), a promising non-invasive imaging technique, proved to be efficient for monitoring in vivo the time course of retinal degeneration in Xenopus larvae [46]. Tam et al. generated a model for RP by causing a mutation in the rhodopsin gene ( $\mathrm{P} 23 \mathrm{H})$, which is known to cause $\mathrm{RP}$ in humans. It was suggested that the $\mathrm{P} 23 \mathrm{H}$ mutant protein is misfolded and retained in the endoplasmic reticulum (ER), leading to ER stress and ultimately causing rod death [47]. Interestingly, when these tadpoles were reared in the dark, the degeneration was rescued [48]. The authors thus suggest that protecting RP patients (with mutations in the $\mathrm{N}$ terminus of rhodopsin) from light could be of therapeutic value. Recently, it was reported that light-induced retinal degeneration caused by $\mathrm{P} 23 \mathrm{H}$ rhodopsin occurs via cell death by autophagy [49•], supporting the hypothesis that multiple cell death mechanisms cause retinal degeneration [50]. Transgenic Xenopus expressing rhodopsin glycosylation mutants (T4K and T17M) exhibit light-exacerbated retinal degeneration, as in humans [51]. These Xenopus models helped demonstrate a novel pathogenic mechanism in which glycosylation-deficient rhodopsins become destabilized by light activation, leading to photoreceptor degeneration. Transgenic Xenopus models expressing mutated rhodopsin that do not lead to degeneration, but are known to cause autosomal dominant congenital night blindness (CNB) in humans, have also contributed to bring insights into the molecular mechanisms of the disease. The authors propose that rhodopsin mutations cause CNB as a result of persistent signaling by the constitutively active opsin [52]. Stargardt-like macular dystrophy is a juvenile macular degeneration caused by mutations in the elongation of very long-chain fatty acids 4
(ELOVL4) gene [53]. A Xenopus transgenic model of this disease, overexpressing dominant negative ELOVL4 variants, has been generated [54]. Although normally present in the inner segments, the truncated protein was shown to be mislocalized to the Golgi compartments or the inner segments. This mislocalization was hypothesized to be responsible for the alteration in photoreceptor outer segment structure and function, resulting in degeneration [54].

\section{Models to Study Retinal Regeneration}

Retinal regenerative studies in zebrafish benefit from a variety of injury paradigms: chemical lesions, physical or genetic methods of ablation, and light or thermal injury. Physical methods, such as surgical removal or needle incision, damage neurons in all retinal layers $[55,56]$. Intravitreal injection of ouabain, a plant-derived $\mathrm{Na} / \mathrm{K}$-ATPase inhibitor, causes retinal degeneration in a dose-dependent manner in zebrafish. It affects either all layers or more selectively the GCL and INL without damaging photoreceptors [57]. To selectively damage neurons in the INL and GCL, NMDA-mediated neurotoxicity has also been used [58 ${ }^{\bullet}$.

To specifically cause photoreceptor loss, there are two widely used light damage paradigms [59-64]. One uses constant bright light, primarily damaging rod photoreceptors, whereas the other uses an exposure to extremely intense ultraviolet (UV) light for a short time period, targeting both rods and cones. More recently, a new light lesion paradigm was designed where light is focused through a microscope onto the retina of an immobilized fish. Such focused light lesion has the advantage of creating a locally restricted area of damage [65]. Local thermal lesions using heated copper wire also allows to locally limit retinal damage, affecting solely the RPE and underlying photoreceptors in the adult zebrafish retina [66]. Another novel paradigm to study photoreceptor regeneration was established based on optical coherence tomographyguided laser photocoagulation, which also induces localized lesions in the outer retina [67]. $N$-Methyl- $N$-nitrosourea (MNU) is an alkylating agent well known for inducing photoreceptor damage in rodents [68]. A similar MNU-induced model has recently been developed in zebrafish, leading to specific rod photoreceptor degeneration, without any significant cone loss $[69,70]$. This MNU-induced damage is less invasive than other chemical methods as it does not require intravitreal injections, but can be dissolved in the tank water of the zebrafish. Finally, transgenic zebrafish have been engineered to allow conditional ablation of rods [71] or of single cone subtypes [72], using the nitroreductase-metronidazole (NTR-MTZ) system [73]. These transgenic zebrafish express the $n t r$ gene under the control of a specific promoter. When the fishes are treated with MTZ, the NTR converts it into a cytotoxic compound that does not diffuse to neighboring cells, thereby resulting in targeted ablation of the NTR- 
expressing cells. This process is reversible, so removing the tadpoles from the MTZ solution allows examination of the regeneration process.

Regeneration studies in Xenopus have extensively relied on mechanical approaches affecting all retinal layers, such as complete retinectomy [74-77, 78•, 79], partial retinal excision $[80,81]$, or simple needle incision (our unpublished data). Several conditional cell ablation transgenic Xenopus models have also been engineered. For instance, a modified inducible procaspase 9 (iCasp9) containing binding domains for the pharmacological compound AP20187 was specifically expressed in the rod photoreceptors of Xenopus laevis. Upon addition of AP20187, dimerization and autoactivation of iCasp9 result in rod cell death [82]. Another inducible model, using the NTR-MTZ system described above, has also been used to conditionally and reversibly ablate rod photoreceptors ( [81] and our unpublished data).

\section{Modes of Regeneration and Repair}

The structure, the cell types, and the function of the retina are largely conserved among vertebrates, yet the regenerative ability varies tremendously among groups and has been lost through evolution. Furthermore, even species that regenerate displaying major differences in the cellular and molecular mechanisms used to do so. In the various lesion paradigms described above, the damaged retina regenerates within several days to weeks in zebrafish and Xenopus. Described below are the different modes of retinal regeneration employed by these species.

\section{From the CMZ}

Retinas of teleost fish and amphibians are continuously growing throughout their lifetime owing to retinal stem and progenitor cells located in the $\mathrm{CMZ}$ at the rim of the retina [83-87]. Recent studies showed the presence of a CMZ-like region in cartilaginous fishes [88, 89], as well as in a reptilian, the painted turtle [90]. However, no CMZ was observed in few specimens of adult lizards and snakes [90]. The CMZ seems to have gradually diminished during vertebrate evolution, being present in the post-hatched bird but not in the adult and absent in mammals [91, 92]. Interestingly, however, a CMZ-like zone was observed in self-organizing human optic cups derived from hESCs, at the junction of the RPE and the neural retina [93•].

The presence of true self-renewing and multipotent neural stem cells in the CMZ was suggested by lineage analysis in Xenopus [26] but was firmly demonstrated in medaka fish, using transplantation experiments and lineage analysis of single cells over a long period of time [26, 28]. Multipotent CMZ cells generate all retinal cell types in Xenopus [26]. In zebrafish, however, they do not give rise to rod photoreceptors $[66,94,95]$. Müller cells are the source of newly born rods throughout the lifetime of the zebrafish retina (described later in this review). Recent lineage analysis suggests that retinal stem cells in the CMZ preferentially undergo asymmetric cell divisions and hence maintain their overall population [96•]. Furthermore, evidence supporting this hypothesis was attained from the recent study using clonal and time-lapse analysis, which showed that after cell division one daughter cell remains as a retinal stem cell in the stem cell niche, while the other daughter cell is pushed centrally to become a retinal progenitor, eventually differentiating [97•].

The CMZ has now been molecularly well characterized in zebrafish and Xenopus. As mentioned in the "Introduction" section, CMZ cells are located in a spatial gradient resembling the temporal sequence of development $[27,66]$. The different zones of the CMZ exhibit different combinations of transcription and post-transcription factors, signaling molecules, and cell cycle genes [27, 66, 98-106]. A comparative analysis of gene expression in the $\mathrm{CMZ}$ and during retinal development suggests that $\mathrm{CMZ}$ retinal stem cells originate from the neural retina-RPE border of the optic cup [101].

It has long been known that retinal injury in fish causes increased cell proliferation in the margin, suggesting that the CMZ contributes to retinal regeneration [107-111]. CMZ cells are however not the only cellular source of retinal repair in fish. Following ouabain-induced lesions, the distinct cone mosaic patterns in different regions of the regenerated retina suggested that newly born cones arise via two spatially and cellular distinct mechanisms [112]. The authors thus suggested that the $\mathrm{CMZ}$ is the major source of the regenerated peripheral retina but not of the central one. As described later in this review, Müller cells are the source of central retina regeneration in the fish. By single-cell lineage analysis in medaka, it was shown that CMZ stem cells maintain an asymmetric mode of cell division following retinal injury, as in the non-injured retina [96•]. Previous studies have suggested that rod photoreceptors are not generated from the CMZ of adult teleost fish $[113,114]$. In agreement with this, it was recently shown in zebrafish following rod cell ablation, and using a lineage tracing analysis of the CMZ stem cell population, that these cells generate all retinal cell types except rod photoreceptors [115]. It remains unclear why there is an increased number of CMZ cells in a rod-degenerative model since they do not contribute to rod neurogenesis [115].

Although the RPE constitutes the major cellular source of regeneration following complete retinectomy in urodele amphibians, both the CMZ and the RPE (see below) participate in the replenishment of the tissue in post-metamorphic $X$. laevis [74, 75]. This different contribution of the CMZ appears to be highly variable even among Xenopus species. Indeed, in Xenopus tropicalis, the entire retina regenerates from the $\mathrm{CMZ}$ [78•]. In Rana pipiens, the CMZ is able to 
replenish specific cell types that were ablated by chemical treatment [116]. Whether this is the case in X. laevis has not been investigated. Interestingly, although there is no CMZ in mammals, the retinal margin was shown to have the potential to remain proliferative, attempting to generate a population of ganglion cells in a mouse model lacking RGC [117].

\section{From the RPE}

The RPE is a monolayer of epithelial cells and has diverse functions such as forming a barrier between the choroid and the neural retina (blood-retina barrier), transporting nutrients, water, and ions from the choroid to the neural retina, phagocytosis of the photoreceptor outer segments, and recycling of the photosensitive opsin molecules for the visual cycle. As it is involved in the maintenance of normal structure and function of the retina, several retinal pathologies result from, or result in, the malfunction of the RPE [118].

RPE transdifferentiation into retina following retinectomy has been well described in the newt, an urodele amphibian [74, 118]. In the anuran X. laevis, the transdifferentiation potential of the RPE was thought to be lost after metamorphosis. It has however now been shown that it still occurs in the adult if the retinal vascular membrane (RVM), consisting of a basement membrane and numerous blood capillaries, is left in the ocular chamber during the retinectomy [75]. The process however differs greatly between the two amphibian species. The surgical removal of the newt retina results in proliferation of RPE cells, which regenerate both RPE and neural retina [119, 120]. In contrast, $X$. laevis RPE cells do not transdifferentiate at their original site. Instead, when the $X$. laevis retina is removed, while retaining the RVM, a subpopulation of RPE cells detach from the Bruch's membrane, migrate to the $\mathrm{RVM}$, proliferate, and form a neuroepithelium layer which generates all different retinal neurons and glial cells thereby regenerating the entire neural retina (Fig. 1d). RPE cells that remain at the original site renew the RPE itself $[74,75]$. Cells that migrate were shown to express Pax6 and acquire multipotency [121]. The presence of the RVM following retinectomy was critical, as the RPE failed to transdifferentiate if the RVM was removed. It was also suggested that the loss of contact with the Bruch's membrane/choroid was critical, as it triggers the expression of pax 6 in RPE cells, allowing them to become multipotent and undergo migration and transdifferentiation in contact to the RVM [75, 121]. There are interesting questions that are now to be addressed, such as the following: What makes some of the RPE cells to stay whereas others migrate and transdifferentiate? What exactly are the presence of the RVM and the absence of the choroid doing to promote the regeneration process?

RPE transdifferentiation into all retinal cell types in adulthood appears to be specific to amphibians. It has indeed never been observed in fish. However, all amphibians are not relying on the RPE to regenerate their retina. As mentioned above, $X$. tropicalis regenerates its entire retina solely from the $\mathrm{CMZ}$ [78•]. Thus, in contrast to X. laevis, the RPE of X. tropicalis appears not to be involved in the regeneration process, even when the RVM remains in the ocular chamber following retinectomy. It is well recognized that in mammals too, RPE cells do not proliferate or self-renew upon injury. However, a study by Salero et al. demonstrated that RPE cells derived from human donors could be activated into multipotent cells that proliferated extensively and self-renewed in vitro. These multipotent cells could generate both neural and mesenchymal progeny in differentiation media that have been used previously to promote different cell types [122]. This study reveals a previously unappreciated plasticity of RPE cells that was thought to apply specifically to amphibians. Under appropriate conditions, mammalian RPE may thus also have the capacity to self-repair.

\section{From Müller Cells}

Müller glial cells form the principle glial cells of the retina (constituting about $90 \%$ of the total glial cells and about $4-5 \%$ of the total retinal cells). They span the entire thickness of the retina from the GCL until the outer limiting membrane (OLM), the boundary between the cell bodies of the photoreceptors from their inner segments. Müller glial cell bodies are present in the INL, and their processes connect with all retinal neurons. Müller cells form a symbiotic metabolic relation with the adjacent photoreceptors, such that they provide the metabolites that are not synthesized within the photoreceptors and vice versa [123]. Müller cells are the last cells to be born during development and are in a quiescent post-mitotic state in Xenopus. Conversely, these cells in zebrafish continue to divide slowly and supply rod photoreceptors to the continuously growing retina $[6,57,62,124]$.

Regardless of the injury paradigm used to damage the retina (see above), Müller glia are the primary source of regenerated neurons in zebrafish $[57,58 \bullet, 66,95,124-129,130$, 131-133]. Retinal functional recovery is however faster, with fewer histological errors, following selective damage that spares a population of neurons, as compared with extensive retinal damage [134]. Following injury, activated Müller cells undergo asymmetric division to self-renew and generate a retinal progenitor cell. The latter proliferates rapidly resulting in a cluster of progenitors which migrate to the area of damage and differentiate into the appropriate retinal cell type (Fig. 1e) $[135,136]$. Indeed, although under normal physiological conditions Müller cells generate only rods, they are able to form all types of retinal neurons following retina damage [94]. It has recently been shown that Müller cells actually regenerate all retinal cell types regardless of which cells are initially damaged. Neurons in excess are then seeded into undamaged retinal layers [58•]. Upon cell cycle re-entry, Müller glial cells 
undergo interkinetic nuclear migration (INM), a process involving migration of nuclei along the apicobasal axis of the retina in phase with the cell cycle [91]. This migration was recently shown to be facilitated by the actin cytoskeleton and Rho-associated coiled-coil kinases (Rocks) and necessary for regeneration to occur [137•].

Reactive gliosis in mammals is beneficial to neurons through the release of a variety of neurotrophic factors that protect neurons from cell death. Prolonged gliosis, however, becomes detrimental and impedes Müller glial regenerative potential [138]. Zebrafish Müller glial cells also exhibit signs of reactive gliosis following retinal injury, prior to acting as stem cells [139]. Interfering with the Müller cell proliferative ability in zebrafish leads to persistent reactive gliosis, including hypertrophy and upregulation of Gfap, temporarily increasing Müller cell neuroprotective functions, but resulting in an inhibition of retinal regeneration [139]. This recent study highlights how modulating the balance between proliferative and non-proliferative gliosis can impact the balance between neuron protection and neuron replacement.

Apoptotic neurons in damaged retina produce factors, such as the secreted pro-inflammatory cytokine $\operatorname{Tnf} \alpha$, to initiate Müller glial proliferation [140]. Müller glial cells respond by re-expressing pluripotency genes such as $c$-myc, nanog, nox2, and oct4 [141]. A recent transcriptomic analysis was made on fluorescence-activated cell sorting (FACS)-sorted Müller glia following retinal lesion [142]. This study revealed several other categories of genes/signaling rapidly upregulated in reactive Müller cells, such as nuclear factor- $\mathrm{KB}(\mathrm{NF}-\mathrm{\kappa B})$ signaling, prostaglandin metabolism, and clock genes. These represent potential novel candidates involved in Müller celldependent regeneration of retinal neurons. Activated Müller glial cells themselves are a source of growth factors and cytokines that drive and amplify their own proliferative activity [143•]. Several regeneration-associated signaling pathways activated in reactive Müller cells and required for their proliferation were identified in the last few years, such as Wnt/ $\beta$ catenin, MAPK-Erk, PI3K/Akt, and Jak-Stat signaling (reviewed in detail in [95, 144]). On the other hand, inhibitory effects of some pathways such as TGF $\beta$ were reported [95]. In support with this, it was recently shown that inhibition of the TGF $\beta$ signaling pathway results in increased Müller cell proliferation following retinal degeneration [145].

Ascl1 is a critical proneural basic helix-loop-helix (bHLH) transcription factor upregulated in Müller cells following retinal damage and required for their proliferation during retinal regeneration $[125,146]$. The different regulatory mode of this gene between mammals and fishes was proposed as one of the reasons underlying the different regenerative ability between these species [147]. It was indeed shown in young mice that forced expression of Ascll in Müller glia could stimulate their capacity for retinal regeneration. Another bHLH factor, Atoh7, was recently shown to be sufficient to trigger a proliferative and neurogenic response of quiescent Müller cells in medaka fish [148].

A key question is whether Müller cell-derived neurons can restore their original connectivity patterns. It was recently shown in zebrafish that regenerated bipolar cells following retinal damage can achieve functional integration in the retina [149•, 150]. However, stereotypic dendritic wiring patterns are not fully re-established. The authors thus propose that regenerated bipolar cells may exhibit visual response properties that do not resemble those of the original population. Regarding horizontal cells, it was shown that following ablation of UV cones, H3 horizontal cells that normally prefer UV cones re-establish contact with newly regenerated UV cones [151]. This study thus demonstrates that the preference of synaptic partners is maintained. This however is true only if lost cones are rapidly replaced, since misconnections are observed if regeneration is delayed.

Many regeneration studies performed in Xenopus involved the removal of the complete retina, thereby preventing the analysis of resident Müller cells during the regenerative process. Although retinal precursor cells were found at the wound site after partial retinal resection in pre-metamorphic $X$. laevis, their Müller cell identity was not investigated [80]. In a model of conditional rod cell ablation, Müller cell hypertrophy was observed suggesting the occurrence of reactive gliosis. Yet, in contrast to the fish situation, no proliferative Müller cells were observed [152]. Recently, however, we were able to show in a similar model of conditional rod cell ablation that $X$. laevis Müller cells are able to re-enter into the cell cycle and contribute to the regeneration of retinal neurons (our unpublished data). Interestingly and unexpectedly, we found that the extent of cell cycle re-entry appears dependent on the age of the animal, being very limited in young tadpoles compared to pre-metamorphic, post-metamorphic, or adult specimen. This may be one element underlying the apparent different results reported so far on Müller cell response in a damaged $X$. laevis retina. Xenopus is thus able to mobilize CMZ cells, RPE cells, or Müller cells according to the injury paradigm.

\section{Conclusions}

Together, these few illustrations highlight that zebrafish and Xenopus models are emerging as key organisms for retinal disease modeling to provide a deeper understanding of the pathogenesis of the disease, identify potential causative genes, and screen for novel drugs. It is expected that CRISPR-Cas9 technology, as a genome-editing tool, will further facilitate the development of such models that mimic retinal degenerative diseases.

The regenerative abilities of the zebrafish and Xenopus are truly remarkable. Species-specific differences in the mode of regeneration are intriguing and deserve further investigations, 
to better understand the evolutionary constrains behind neural tissue regeneration. Studies involving comparative evolutionary approaches could bring insights into the molecular cues that either sustain or prevent neural cell replacement and therefore help to design and develop therapies to stimulate retinal regeneration in mammals.

Acknowledgements The authors thank Nareh Sahakian for her comments on this review. M.P.'s laboratory is supported by grants from the FRM, Association Retina France, and Fondation Valentin Haüy.

\section{Compliance with Ethical Standards}

Conflict of Interest Divya Ail and Muriel Perron declare that they have no conflict of interest.

Human and Animal Rights and Informed Consent This article does not contain any studies with human or animal subjects performed by any of the authors

Open Access This article is distributed under the terms of the Creative Commons Attribution 4.0 International License (http:// creativecommons.org/licenses/by/4.0/), which permits unrestricted use, distribution, and reproduction in any medium, provided you give appropriate credit to the original author(s) and the source, provide a link to the Creative Commons license, and indicate if changes were made.

\section{References}

Recently published papers of particular interest have been highlighted as:

\section{- Of importance}

1. Bainbridge JW, Mehat MS, Sundaram V, Robbie SJ, Barker SE, Ripamonti C et al (2015) Long-term effect of gene therapy on Leber's congenital amaurosis. N Engl J Med 372(20):1887-1897

2. Dejneka NS, Surace EM, Aleman TS, Cideciyan AV, Lyubarsky A, Savchenko A et al (2004) In utero gene therapy rescues vision in a murine model of congenital blindness. Mol Ther 9(2):182188

3. Fahim AT, Daiger SP, Weleber RG (2013) Retinitis pigmentosa overview. In: Pagon RA, Adam MP, Ardinger HH, Wallace SE, Amemiya A, Bean LJH, Bird TD, Ledbetter N, Mefford HC, Smith RJH, Stephens K (eds) GeneReviews. University of Washington, Seattle

4. Lambert NG, ElShelmani H, Singh MK, Mansergh FC, Wride MA, Padilla $\mathrm{M}$ et al (2016) Risk factors and biomarkers of agerelated macular degeneration. Prog Retin Eye Res 54:64-102

5. Seddon JM, Chen CA (2004) The epidemiology of age-related macular degeneration. Int Ophthalmol Clin 44(4):17-39

6. Grassmann F, Fauser S, Weber BH (2015) The genetics of agerelated macular degeneration (AMD) - novel targets for designing treatment options? Eur J Pharm Biopharm 95(Pt B):194-202

7. Dixon JA, Oliver SC, Olson JL, Mandava N (2009) VEGF TrapEye for the treatment of neovascular age-related macular degeneration. Expert Opin Investig Drugs 18(10):1573-1580

8. Mitchell P (2011) A systematic review of the efficacy and safety outcomes of anti-VEGF agents used for treating neovascular age- related macular degeneration: comparison of ranibizumab and bevacizumab. Curr Med Res Opin 27(7):1465-1475

9. Bernstein PS, Li B, Vachali PP, Gorusupudi A, Shyam R, Henriksen BS et al (2016) Lutein, zeaxanthin, and meso-zeaxanthin: the basic and clinical science underlying carotenoid-based nutritional interventions against ocular disease. Prog Retin Eye Res 50:34-66

10. Jayakody SA, Gonzalez-Cordero A, Ali RR, Pearson RA (2015) Cellular strategies for retinal repair by photoreceptor replacement. Prog Retin Eye Res 46:31-66

11. Reh TA (2016) Photoreceptor transplantation in late stage retinal degeneration. Invest Ophthalmol Vis Sci 57: ORSFg1-ORSFg7

12. Pearson RA, Barber AC, Rizzi M, Hippert C, Xue T, West EL et al (2012) Restoration of vision after transplantation of photoreceptors. Nature 485(7396):99-103

13. Gonzalez-Cordero A, West EL, Pearson RA, Duran Y, Carvalho LS, Chu CJ et al (2013) Photoreceptor precursors derived from three-dimensional embryonic stem cell cultures integrate and mature within adult degenerate retina. Nat Biotechnol 31(8):741-747

14. Shirai H, Mandai M, Matsushita K, Kuwahara A, Yonemura S, Nakano T et al (2016) Transplantation of human embryonic stem cell-derived retinal tissue in two primate models of retinal degeneration. Proc Natl Acad Sci U S A 113(1):E81-E90. This is a pilot study in primate models evaluating the clinical feasibility of transplantation of hESC-derived retinal sheets.

15. Carr AJ, Vugler AA, Hikita ST, Lawrence JM, Gias C, Chen LL et al. (2009) Protective effects of human iPS-derived retinal pigment epithelium cell transplantation in the retinal dystrophic rat. PLoS One 4(12):e8152

16. Siqueira RC, Messias A, Voltarelli JC, Scott IU, Jorge R (2011) Intravitreal injection of autologous bone marrow-derived mononuclear cells for hereditary retinal dystrophy: a phase I trial. Retina 31(6):1207-1214

17. Buchholz DE, Hikita ST, Rowland TJ, Friedrich AM, Hinman CR, Johnson LV et al (2009) Derivation of functional retinal pigmented epithelium from induced pluripotent stem cells. Stem Cells 27(10):2427-2434

18. Hirami Y, Osakada F, Takahashi K, Okita K, Yamanaka S, Ikeda H et al (2009) Generation of retinal cells from mouse and human induced pluripotent stem cells. Neurosci Lett 458(3):126-131

19. Schwartz SD, Hubschman JP, Heilwell G, Franco-Cardenas V, Pan CK, Ostrick RM et al (2012) Embryonic stem cell trials for macular degeneration: a preliminary report. Lancet 379(9817): 713-720

20. Song WK, Park K-M, Kim H-J, Lee JH, Choi J, Chong SY et al (2015) Treatment of macular degeneration using embryonic stem cell-derived retinal pigment epithelium: preliminary results in Asian patients. Stem cell reports 4(5):860-872

21. Schwartz SD, Regillo CD, Lam BL, Eliott D, Rosenfeld PJ, Gregori NZ et al (2015) Human embryonic stem cell-derived retinal pigment epithelium in patients with age-related macular degeneration and Stargardt's macular dystrophy: follow-up of two open-label phase 1/2 studies. Lancet 385(9967):509-516. This study reports on the safety, graft survival, and possible biological activity of hESCderived RPE cells transplanted in patients.

22. Pearson RA, Gonzalez-Cordero A, West EL, Ribeiro JR, Aghaizu N, Goh D et al (2016) Donor and host photoreceptors engage in material transfer following transplantation of post-mitotic photoreceptor precursors. Nat Commun 7:13029. Together with the Santos-Ferreira et al. study, this paper demonstrated for the first time that transplanted photoreceptors do not integrate into the retina but engage in exchange of cytoplasmic material with host cells.

23. Santos-Ferreira T, Llonch S, Borsch O, Postel K, Haas J, Ader M (2016) Retinal transplantation of photoreceptors results in donor- 
host cytoplasmic exchange. Nat Commun 7:13028. Together with the Pearson et al. study, this paper demonstrated for the first time that transplanted photoreceptors do not integrate into the retina but engage in exchange of cytoplasmic material with host cells.

24. Luo YH, da Cruz L (2016) The Argus((R)) II retinal prosthesis system. Prog Retin Eye Res 50:89-107

25. Turner DL, Cepko CL (1987) A common progenitor for neurons and glia persists in rat retina late in development. Nature 328(6126):131-136

26. Wetts R, Serbedzija GN, Fraser SE (1989) Cell lineage analysis reveals multipotent precursors in the ciliary margin of the frog retina. Dev Biol 136(1):254-263

27. Perron M, Kanekar S, Vetter ML, Harris WA (1998) The genetic sequence of retinal development in the ciliary margin of the Xenopus eye. Dev Biol 199(2):185-200

28. Centanin L, Hoeckendorf B, Wittbrodt J (2011) Fate restriction and multipotency in retinal stem cells. Cell Stem Cell 9(6):553-562

29. Link BA, Collery RF (2015) Zebrafish models of retinal disease. Annu Rev Vis Sci 1(1):125-153. This is an excellent and comprehensive review on zebrafish models for retinal diseases.

30. Bibliowicz J, Tittle RK, Gross JM (2011) Toward a beter understanding of human eye disease insights from the zebra fish, Daniorerio. Prog Mol Biol Transl Sci 100:287-330.

31. Chhetri J, Jacobson G, Gueven N (2014) Zebrafish — on the move towards ophthalmological research. Eye 28(4):367-380

32. Stearns G, Evangelista M, Fadool JM, Brockerhoff SE (2007) A mutation in the cone-specific pde 6 gene causes rapid cone photoreceptor degeneration in zebrafish. J Neurosci 27(50):1386613874

33. Viringipurampeer IA, Shan X, Gregory-Evans K, Zhang JP, Mohammadi Z, Gregory-Evans CY (2014) Rip3 knockdown rescues photoreceptor cell death in blind pde $6 \mathrm{c}$ zebrafish. Cell Death Differ 21(5):665-675

34. Stoetzel C, Bär S, De Craene J-O, Scheidecker S, Etard C, Chicher J et al (2016) A mutation in VPS15 (PIK3R4) causes a ciliopathy and affects IFT20 release from the cis-Golgi. Nat Commun 7: 13586. This is a good example of the benefit of zebrafish as a model for human ciliopathies.

35. Heon E, Kim G, Qin S, Garrison JE, Tavares E, Vincent A et al (2016) Mutations in C8ORF37 cause Bardet Biedl syndrome (BBS21). Hum Mol Genet 25(11):2283-2294. This paper nicely illustrates the usefulness of zebrafish for phenotype-genotype correlation studies.

36. Song P, Dudinsky L, Fogerty J, Gaivin R, Perkins BD (2016) Arl13b interacts with Vangl2 to regulate cilia and photoreceptor outer segment length in zebrafish. Investig Opthalmology Vis Sci 57(10):4517

37. Wheway G, Schmidts M, Mans DA, Szymanska K, Nguyen T-MT, Racher H et al (2015) An siRNA-based functional genomics screen for the identification of regulators of ciliogenesis and ciliopathy genes. Nat Cell Biol 17(8):1074-1087. This work illustrates the advantage of zebrafish for large-scale screening approaches, to identify roles of genes involved in retinal diseases.

38. Cao Z, Jensen LD, Rouhi P, Hosaka K, Lanne T, Steffensen JF et al (2010) Hypoxia-induced retinopathy model in adult zebrafish. Nat Protoc 5(12):1903-1910

39. Cao R, Jensen LD, Soll I, Hauptmann G, Cao Y (2008) Hypoxiainduced retinal angiogenesis in zebrafish as a model to study retinopathy. PLoS One 3(7):e2748

40. van Rooijen E, Voest EE, Logister I, Bussmann J, Korving J, van Eeden FJ et al (2010) von Hippel-Lindau tumor suppressor mutants faithfully model pathological hypoxia-driven angiogenesis and vascular retinopathies in zebrafish. Dis Model Mech 3(5-6): 343-353
41. Gleeson M, Connaughton V, Arneson LS (2007) Induction of hyperglycaemia in zebrafish (Danio rerio) leads to morphological changes in the retina. Acta Diabetol 44(3):157-163

42. Alvarez Y, Chen K, Reynolds AL, Waghorne N, O'Connor JJ, Kennedy BN (2010) Predominant cone photoreceptor dysfunction in a hyperglycaemic model of non-proliferative diabetic retinopathy. Dis Model Mech 3(3-4):236-245

43. Rezzola S, Paganini G, Semeraro F, Presta M, Tobia C (2016) Zebrafish (Danio rerio) embryo as a platform for the identification of novel angiogenesis inhibitors of retinal vascular diseases. Biochim Biophys Acta - Mol Basis Dis 1862(7):1291-1296

44. Lee DC, Vazquez-Chona FR, Ferrell WD, Tam BM, Jones BW, Marc RE et al (2012) Dysmorphic photoreceptors in a P23H mutant rhodopsin model of retinitis pigmentosa are metabolically active and capable of regenerating to reverse retinal degeneration. J Neurosci 32(6):2121-2128

45. Tam BM, Lai CC-L, Zong Z, Moritz OL (2013) Generation of transgenic $X$. laevis models of retinal degeneration. Methods Mol Biol 935:113-125

46. Lee DC, Xu J, Sarunic MV, Moritz OL (2010) Fourier domain optical coherence tomography as a noninvasive means for in vivo detection of retinal degeneration in Xenopus laevis tadpoles. Investig Opthalmology Vis Sci 51(2):1066

47. Tam BM, Moritz OL (2006) Characterization of rhodopsin P23Hinduced retinal degeneration in a Xenopus laevis model of retinitis pigmentosa. Invest Ophthalmol Vis Sci 47(8):3234-3241

48. Tam BM, Moritz OL (2007) Dark rearing rescues P23H rhodopsininduced retinal degeneration in a transgenic Xenopus laevis model of retinitis pigmentosa: a chromophore-dependent mechanism characterized by production of $\mathrm{N}$-terminally truncated mutant rhodopsin. J Neurosci 27(34):9043-9053

49. Bogéa TH, Wen RH, Moritz OL (2015) Light induces ultrastructural changes in rod outer and inner segments, including autophagy, in a transgenic Xenopus laevis $\mathrm{P} 23 \mathrm{H}$ rhodopsin model of retinitis pigmentosa. Investig Opthalmology Vis Sci 56(13): 7947. This study is a good example of the benefit of Xenopus to study the mechanisms underlying photoreceptor cell death in a model of retinitis pigmentosa.

50. Arango-Gonzalez B, Trifunović D, Sahaboglu A, Kranz K, Michalakis S, Farinelli P, et al (2014) Identification of a common non-apoptotic cell death mechanism in hereditary retinal degeneration. Strauß O, editor. PLoS One 9(11):e112142

51. Tam BM, Noorwez SM, Kaushal S, Kono M, Moritz OL (2014) Photoactivation-induced instability of rhodopsin mutants T4K and $\mathrm{T} 17 \mathrm{M}$ in rod outer segments underlies retinal degeneration in $X$. laevis transgenic models of retinitis pigmentosa. J Neurosci 34(40):13336-13348

52. Jin S, Cornwall MC, Oprian DD (2003) Opsin activation as a cause of congenital night blindness. Nat Neurosci 6(7):731-735

53. Bennett LD, Anderson RE (2016) Current progress in deciphering importance of VLC-PUFA in the retina. Adv Exp Med Biol 854: $145-151$

54. Agbaga MP, Tam BM, Wong JS, Yang LL, Anderson RE, Moritz OL (2014) Mutant ELOVL4 that causes autosomal dominant stargardt-3 macular dystrophy is misrouted to rod outer segment disks. Invest Ophthalmol Vis Sci 55(6):3669-3680

55. Cameron DA Cellular proliferation and neurogenesis in the injured retina of adult zebrafish. Vis Neurosci 17(5):789-797

56. Senut M-C, Gulati-Leekha A, Goldman D (2004) An element in the 1-tubulin promoter is necessary for retinal expression during optic nerve regeneration but not after eye injury in the adult zebrafish. J Neurosci 24(35):7663-7673

57. Fimbel SM, Montgomery JE, Burket CT, Hyde DR (2007) Regeneration of inner retinal neurons after intravitreal injection of ouabain in zebrafish. J Neurosci 27(7):1712-1724 
58. Powell C, Cornblath E, Elsaeidi F, Wan J, Goldman D (2016) Zebrafish Müller glia-derived progenitors are multipotent, exhibit proliferative biases and regenerate excess neurons. Sci Rep 6: 24851. Based on the use of different retinal injury paradigms, this study revealed that in addition to regenerate lost retinal cells, Müller glia-derived progenitors also generate unneeded neurons.

59. Vihtelic TS, Soverly JE, Kassen SC, Hyde DR (2006) Retinal regional differences in photoreceptor cell death and regeneration in light-lesioned albino zebrafish. Exp Eye Res 82(4):558-575

60. Vihtelic TS, Hyde DR (2000) Light-induced rod and cone cell death and regeneration in the adult albino zebrafish (Danio rerio) retina. J Neurobiol 44(3):289-307

61. Kassen SC, Ramanan V, Montgomery JE, Burket TC, Liu C-G, Vihtelic TS et al (2007) Time course analysis of gene expression during light-induced photoreceptor cell death and regeneration in albino zebrafish. Dev Neurobiol 67(8):1009-1031

62. Bernardos RL, Barthel LK, Meyers JR, Raymond PA (2007) Late-stage neuronal progenitors in the retina are radial Muller glia that function as retinal stem cells. J Neurosci 27(26): 7028-7040

63. Thomas JL, Nelson CM, Luo X, Hyde DR, Thummel R (2012) Characterization of multiple light damage paradigms reveals regional differences in photoreceptor loss. Exp Eye Res 97(1):105116

64. Rajaram K, Summerbell ER, Patton JG (2014) Technical brief: constant intense light exposure to lesion and initiate regeneration in normally pigmented zebrafish. Mol Vis 20:1075-1084

65. Weber A, Hochmann S, Cimalla P, Gärtner M, Kuscha V, Hans S, et al (2013) Characterization of light lesion paradigms and optical coherence tomography as tools to study adult retina regeneration in zebrafish. Neuhauss SC, editor. PLoS One 8(11):e80483

66. Raymond PA, Barthel LK, Bernardos RL, Perkowski JJ (2006) Molecular characterization of retinal stem cells and their niches in adult zebrafish. BMC Dev Biol 6:36

67. DiCicco RM, Bell BA, Kaul C, Hollyfield JG, Anand-Apte B, Perkins BD et al (2014) Retinal regeneration following OCTguided laser injury in zebrafish. Invest Ophthalmol Vis Sci 55(10):6281-6288

68. Tsubura A, Yoshizawa K, Kuwata M, Uehara N (2010) Animal models for retinitis pigmentosa induced by MNU; disease progression, mechanisms and therapeutic trials. Histol Histopathol 25(7): 933-944

69. Tappeiner C, Balmer J, Iglicki M, Schuerch K, Jazwinska A, Enzmann V, et al (2013) Characteristics of rod regeneration in a novel zebrafish retinal degeneration model using $\mathrm{N}$ methyl-N-nitrosourea (MNU). Thummel R, editor. PLoS One 8(8):e71064

70. Maurer E, Tschopp M, Tappeiner C, Sallin P, Jazwinska A, Enzmann V (2014) Methylnitrosourea (MNU)-induced retinal degeneration and regeneration in the zebrafish: histological and functional characteristics. J Vis Exp (92):e51909

71. Montgomery JE, Parsons MJ, Hyde DR (2010) A novel model of retinal ablation demonstrates that the extent of rod cell death regulates the origin of the regenerated zebrafish rod photoreceptors. J Comp Neurol 518(6):800-814

72. Fraser B, DuVal MG, Wang H, Allison WT (2013) Regeneration of cone photoreceptors when cell ablation is primarily restricted to a particular cone subtype. Karl MO, editor. PLoS One 8(1):e55410

73. Curado S, Stainier DYR, Anderson RM (2008) Nitroreductasemediated cell/tissue ablation in zebrafish: a spatially and temporally controlled ablation method with applications in developmental and regeneration studies. Nat Protoc 3(6):948-954
74. Araki M (2007) Regeneration of the amphibian retina: role of tissue interaction and related signaling molecules on RPE transdifferentiation. Develop Growth Differ 49(2):109-120

75. Yoshii C, Ueda Y, Okamoto M, Araki M (2007) Neural retinal regeneration in the anuran amphibian Xenopus laevis post-metamorphosis: transdifferentiation of retinal pigmented epithelium regenerates the neural retina. Dev Biol 303(1):45-56

76. Vergara MN, Del Rio-Tsonis K (2009) Retinal regeneration in the Xenopus laevis tadpole: a new model system. Mol Vis 15:1000 1013

77. Ueda Y, Mizuno N, Araki M (2012) Transgenic Xenopus laevis with the ef1- $\alpha$ promoter as an experimental tool for amphibian retinal regeneration study. Genesis 50(8):642-650

78. Miyake A, Araki M (2014) Retinal stem/progenitor cells in the ciliary marginal zone complete retinal regeneration: a study of retinal regeneration in a novel animal model. Dev Neurobiol. 74(7):739-756. This study revealed that the entire retina can regenerate after complete retinectomy in adult $X$. tropicalis. This work also highlighted differences in the regeneration process between $X$. laevis and $X$. tropicalis.

79. Filoni $\mathrm{S}$ (2009) Retina and lens regeneration in anuran amphibians. Semin Cell Dev Biol 20(5):528-534

80. Martinez-De Luna RI, Kelly LE, El-Hodiri HM (2011) The Retinal Homeobox $(\mathrm{Rx})$ gene is necessary for retinal regeneration. Dev Biol 353(1):10-18

81. Lee DC, Hamm LM, Moritz OL (2013) Xenopus laevis tadpoles can regenerate neural retina lost after physical excision but cannot regenerate photoreceptors lost through targeted ablation. Invest Ophthalmol Vis Sci 54(3):1859-1867

82. Hamm LM, Tam BM, Moritz OL (2009) Controlled rod cell ablation in transgenic Xenopus laevis. Invest Ophthalmol Vis Sci 50(2):885-892

83. Johns PR (1977) Growth of the adult goldfish eye. III. Source of the new retinal cells. J Comp Neurol 176(3):343-357

84. Straznicky K, Gaze RM (1971) The growth of the retina in Xenopus laevis: an autoradiographic study. J Embryol Exp Morphol 26(1):67-79

85. Fischer AJ, Bosse JL, El-Hodiri HM (2013) The ciliary marginal zone (CMZ) in development and regeneration of the vertebrate eye. Exp Eye Res 116:199-204

86. Hollyfield JG (1968) Differential addition of cells to the retina in Rana pipiens tadpoles. Dev Biol 18(2):163-179

87. Hollyfield JG (1971) Differential growth of the neural retina in Xenopus laevis larvae. Dev Biol 24(2):264-286

88. Sánchez-Farías N, Candal E (2016) Identification of radial glia progenitors in the developing and adult retina of sharks. Front Neuroanat 20:10

89. Ferreiro-Galve S, Rodríguez-Moldes I, Anadón R, Candal E (2010) Patterns of cell proliferation and rod photoreceptor differentiation in shark retinas. J Chem Neuroanat 39(1):1-14

90. Todd L, Suarez L, Squires N, Zelinka CP, Gribbins K, Fischer AJ (2016) Comparative analysis of glucagonergic cells, glia, and the circumferential marginal zone in the reptilian retina. J Comp Neurol 524(1):74-89

91. Kubota R, Hokoc JN, Moshiri A, McGuire C, Reh TA (2002) A comparative study of neurogenesis in the retinal ciliary marginal zone of homeothermic vertebrates. Brain Res Dev Brain Res 134(1-2):31-41

92. Fischer AJ, Reh TA (2000) Identification of a proliferating marginal zone of retinal progenitors in postnatal chickens. Dev Biol 220(2):197-210

93. Kuwahara A, Ozone C, Nakano T, Saito K, Eiraku M, Sasai Y (2015) Generation of a ciliary margin-like stem cell niche from self-organizing human retinal tissue. Nat Commun 6:6286. This study revealed the presence of a CMZ-like region in human retinal tissue generated in vitro. 
94. Stenkamp DL (2011) The rod photoreceptor lineage of teleost fish. Prog Retin Eye Res 30(6):395-404

95. Lenkowski JR, Raymond PA (2014) Muller glia: stem cells for generation and regeneration of retinal neurons in teleost fish. Prog Retin Eye Res 40:94-123

96. Centanin L, Ander JJ, Hoeckendorf B, Lust K, Kellner T, Kraemer I et al (2014) Exclusive multipotency and preferential asymmetric divisions in post-embryonic neural stem cells of the fish retina. Development 141(18):3472-3482. This study revealed that retinal stem cells in the CMZ preferentially divide asymmetrically both during tissue growth and during regeneration.

97. Wan Y, Almeida AD, Rulands S, Chalour N, Muresan L, Wu Y et al (2016) The ciliary marginal zone of the zebrafish retina: clonal and time-lapse analysis of a continuously growing tissue. Development 143(7):1099-1107. This time-lapse analysis showed that CMZ stem cells divide assymetrically in a radial orientation to generate one stem cell that stays in the peripheral niche and a progenitor that moves centrally and differentiates.

98. Amato MA, Boy S, Arnault E, Girard M, Della Puppa A, Sharif A et al (2005) Comparison of the expression patterns of five neural RNA binding proteins in the Xenopus retina. J Comp Neurol 481(4):331-339

99. Agathocleous M, Harris WA (2009) From progenitors to differentiated cells in the vertebrate retina. Annu Rev Cell Dev Biol 25(1): 45-69

100. Harris WA, Perron M (1998) Molecular recapitulation: the growth of the vertebrate retina. Int J Dev Biol 42(3):299-304

101. El Yakoubi W, Borday C, Hamdache J, Parain K, Tran HT, Vleminckx K et al (2012) Hes4 controls proliferative properties of neural stem cells during retinal ontogenesis. Stem Cells 30(12): 2784-2795

102. Borday C, Cabochette P, Parain K, Mazurier N, Janssens S, Tran HT et al (2012) Antagonistic cross-regulation between Wnt and Hedgehog signalling pathways controls post-embryonic retinal proliferation. Development 139(19):3499-3509

103. Wehman AM, Staub W, Meyers JR, Raymond PA, Baier H (2005) Genetic dissection of the zebrafish retinal stem-cell compartment. Dev Biol 281(1):53-65

104. Cerveny KL, Varga M, Wilson SW (2012) Continued growth and circuit building in the anamniote visual system. Dev Neurobiol. 72(3):328-345

105. Casarosa S, Leone P, Cannata S, Santini F, Pinchera A, Barsacchi $G$ et al (2005) Genetic analysis of metamorphic and premetamorphic Xenopus ciliary marginal zone. Dev Dyn 233(2):646-651

106. Ohnuma S, Hopper S, Wang KC, Philpott A, Harris WA (2002) Co-ordinating retinal histogenesis: early cell cycle exit enhances early cell fate determination in the Xenopus retina. Development 129(10):2435-2446

107. Maier W, Wolburg H (1979) Regeneration of the goldfish retina after exposure to different doses of ouabain. Cell Tissue Res 202(1):99-118

108. Kurz-Isler G, Wolburg H (1982) Morphological study on the regeneration of the retina in the rainbow trout after ouabain-induced damage: evidence for dedifferentiation of photoreceptors. Cell Tissue Res 225(1):165-178

109. Negishi K, Teranishi T, Kato S, Nakamura Y (1987) Paradoxical induction of dopaminergic cells following intravitreal injection of high doses of 6-hydroxydopamine in juvenile carp retina. Brain Res 430(1):67-79

110. Raymond PA, Reifler MJ, Rivlin PK (1988) Regeneration of goldfish retina: rod precursors are a likely source of regenerated cells. J Neurobiol 19(5):431-463
111. Hitchcock PF, Lindsey Myhr KJ, Easter SSJ, Mangione-Smith R, Jones DD (1992) Local regeneration in the retina of the goldfish. J Neurobiol 23(2):187-203

112. Stenkamp DL, Powers MK, Carney LH, Cameron DA (2001) Evidence for two distinct mechanisms of neurogenesis and cellular pattern formation in regenerated goldfish retinas. J Comp Neurol 431(4):363-381

113. Johns PR (1982) Formation of photoreceptors in larval and adult goldfish. J Neurosci 2(2):178-198

114. Otteson DC, D'Costa AR, Hitchcock PF (2001) Putative stem cells and the lineage of rod photoreceptors in the mature retina of the goldfish. Dev Biol 232(1):62-76

115. Wilson SG, Wen W, Pillai-Kastoori L, Morris AC (2016) Tracking the fate of her4 expressing cells in the regenerating retina using her4:Kaede zebrafish. Exp Eye Res 145:75-87

116. Reh TA (1987) Cell-specific regulation of neuronal production in the larval frog retina. J Neurosci 7(10):3317-3324

117. Kiyama T, Li H, Gupta M, Lin Y-P, Chuang AZ, Otteson DC et al (2012) Distinct neurogenic potential in the retinal margin and the pars plana of mammalian eye. J Neurosci 32(37):12797-12807

118. Chiba C (2014) The retinal pigment epithelium: an important player of retinal disorders and regeneration. Exp Eye Res 123:107-114

119. Moshiri A, Close J, Reh TA (2004) Retinal stem cells and regeneration. Int J Dev Biol. 48(8-9):1003-1014

120. Stone LS, Steinitz H (1957) Regeneration of neural retina and lens from retina pigment cell grafts in adult newts. J Exp Zool 135(2): 301-317

121. Kuriyama F, Ueda Y, Araki M (2009) Complete reconstruction of the retinal laminar structure from a cultured retinal pigment epithelium is triggered by altered tissue interaction and promoted by overlaid extracellular matrices. Dev Neurobiol. 69(14):950-958

122. Salero E, Blenkinsop TA, Corneo B, Harris A, Rabin D, Stern JH et al (2012) Adult human RPE can be activated into a multipotent stem cell that produces mesenchymal derivatives. Cell Stem Cell 10(1):88-95

123. Hurley JB, Lindsay KJ, Du J (2015) Glucose, lactate, and shuttling of metabolites in vertebrate retinas. J Neurosci Res 93(7):10791092

124. Fausett BV, Goldman D (2006) A role for 1 tubulin-expressing Muller glia in regeneration of the injured zebrafish retina. J Neurosci 26(23):6303-6313

125. Fausett BV, Gumerson JD, Goldman D (2008) The proneural basic helix-loop-helix gene asclla is required for retina regeneration. J Neurosci 28(5):1109-1117

126. Thummel R, Kassen SC, Montgomery JE, Enright JM, Hyde DR (2008) Inhibition of Müller glial cell division blocks regeneration of the light-damaged zebrafish retina. Dev Neurobiol 68(3):392408

127. Thummel R, Kassen SC, Enright JM, Nelson CM, Montgomery JE, Hyde DR (2008) Characterization of Müller glia and neuronal progenitors during adult zebrafish retinal regeneration. Exp Eye Res 87(5):433-444

128. Ogai K, Hisano S, Sugitani K, Koriyama Y, Kato S (2016) Cell fate of Müller cells during photoreceptor regeneration in an Nnethyl-N-nitrosourea-induced retinal degeneration model of zebrafish. In: Advances in experimental medicine and biology, pp. 685-692

129. Nelson CM, Hyde DR (2012) Müllerglia as a source of neuronal progenitor cells to regenerate the damaged zebrafish retina. Adv Exp Med Biol 723:425-430

130. Goldman D (2014) Müllerglial cell reprogramming and retina regeneration. Nat Rev Neurosci 15(7):431-442. This is an excellent review on factors and signaling pathways that contribute to Müller glial cell reprogramming and proliferation in different species. 
131. Gorsuch RA, Hyde DR (2014) Regulation of Müller glial dependent neuronal regeneration in the damaged adult zebrafish retina. Exp Eye Res 123:131-140

132. Hamon A, Roger JE, Yang X-J, Perron M (2016) Müller glial celldependent regeneration of the neural retina: an overview across vertebrate model systems. Dev Dyn 245(7):727-738

133. Chohan A, Singh U, Kumar A, Kaur J (2017) Müller stem cell dependent retinal regeneration. Clin Chim Acta 464:160-164

134. Sherpa T, Lankford T, McGinn TE, Hunter SS, Frey RA, Sun C et al (2014) Retinal regeneration is facilitated by the presence of surviving neurons. Dev Neurobiol 74(9):851-876

135. Lahne M, Hyde DR (2016) Interkinetic nuclear migration in the regenerating retina. Adv Exp Med Biol 854:587-593

136. Nagashima M, Barthel LK, Raymond PA (2013) A self-renewing division of zebrafish Muller glial cells generates neuronal progenitors that require $\mathrm{N}$-cadherin to regenerate retinal neurons. Development 140(22):4510-4521

137. Lahne M, Li J, Marton RM, Hyde DR (2015) Actin-cytoskeletonand rock-mediated INM are required for photoreceptor regeneration in the adult zebrafish retina. J Neurosci 35(47):15612-15634. This study sheds light on the mechanism of interkinetic migration of Müller cells and Müller cell-derived progenitors during regeneration.

138. Bringmann A, Pannicke T, Grosche J, Francke M, Wiedemann P, Skatchkov S et al (2006) Müller cells in the healthy and diseased retina. Prog Retin Eye Res 25(4):397-424

139. Thomas JL, Ranski AH, Morgan GW, Thummel R (2016) Reactive gliosis in the adult zebrafish retina. Exp Eye Res 143: 98-109

140. Nelson CM, Ackerman KM, O’Hayer P, Bailey TJ, Gorsuch RA, Hyde DR (2013) Tumor necrosis factor-alpha is produced by dying retinal neurons and is required for Muller glia proliferation during zebrafish retinal regeneration. J Neurosci 33(15):65246539

141. Ramachandran R, Fausett BV, Goldman D (2010) Ascl1a regulates Muller glia dedifferentiation and retinal regeneration through a Lin-28-dependent, let-7 microRNA signalling pathway. Nat Cell Biol 12(11):1101-1107

142. Sifuentes CJ, Kim J-W, Swaroop A, Raymond PA (2016) Rapid, dynamic activation of Müller glial stem cell responses in zebrafish. Investig Opthalmology Vis Sci 57(13):5148
143. Wan J, Zhao X-F, Vojtek A, Goldman D (2014) Retinal injury, growth factors, and cytokines converge on $\beta$-catenin and pStat3 signaling to stimulate retina regeneration. Cell Rep 9(1):285-297. This study provides important insights into cross talk between growth factors and cytokine signaling required for Müller cell proliferation in response to retinal injury.

144. Wan J, Goldman D (2016) Retina regeneration in zebrafish. Curr Opin Genet Dev 40:41-47

145. Tappeiner C, Maurer E, Sallin P, Bise T, Enzmann V, Tschopp M (2016) Inhibition of the TGF $\beta$ pathway enhances retinal regeneration in adult zebrafish. Thummel R, editor. PLoS One 11(11): e0167073

146. Ramachandran R, Zhao X-F, Goldman D (2012) Insm1a-mediated gene repression is essential for the formation and differentiation of Müller glia-derived progenitors in the injured retina. Nat Cell Biol 14(10):1013-1023

147. Ueki Y, Wilken MS, Cox KE, Chipman L, Jorstad N, Sternhagen $\mathrm{K}$ et al (2015) Transgenic expression of the proneural transcription factor Ascl1 in Müller glia stimulates retinal regeneration in young mice. Proc Natl Acad Sci 112(44):13717-13722

148. Lust K, Sinn R, Pérez Saturnino A, Centanin L, Wittbrodt J (2016) De novo neurogenesis by targeted expression of atoh7 to Müller glia cells. Development 143(11):1874-1883

149. D'Orazi FD, Zhao X-F, Wong RO, Yoshimatsu T (2016) Mismatch of synaptic patterns between neurons produced in regeneration and during development of the vertebrate retina. Curr Biol 26(17):22682279. This study revealed that the synaptic connections of cells lost following degeneration are not always reestablished after regeneration.

150. Raymond PA (2016) Regeneration: new neurons wire up. Curr Biol 26(17):R794-R796

151. Yoshimatsu T, Williams PR, D’Orazi FD, Suzuki SC, Fadool JM, Allison WT et al (2014) Transmission from the dominant input shapes the stereotypic ratio of photoreceptor inputs onto horizontal cells. Nat Commun 5:3699

152. Choi RY, Engbretson GA, Solessio EC, Jones GA, Coughlin A, Aleksic I et al (2011) Cone degeneration following rod ablation in a reversible model of retinal degeneration. Invest Ophthalmol Vis Sci 52(1):364-373 